INDONESIAN JOURNAL OF MEDICAL SCIENCES AND PUBLIC HEALTH

2020, Vol. 1, No. 1, $13-19$

http://dx.doi.org/10.11594/ijmp.01.01.03

Review Article

\title{
Usage of Inhaled Nitric Oxides in Cases of Eisenmenger Syndrome
}

\author{
Neny Triastuti $1 *$, Muhammad Perdana Airlangga ${ }^{2}$, Muhammad Anas ${ }^{3}$ \\ ${ }^{1}$ Department of Pharmacology, Medical Faculty of University Muhammadiyah of Surabaya 60113, \\ Indonesia \\ ${ }^{2}$ Department of Cardiology, Medical Faculty of University Muhammadiyah of Surabaya 60113, Indonesia \\ 3 Department of Obstetric Gynecologic, Medical Faculty of University Muhammadiyah of Surabaya 60113, \\ Indonesia
}

Article history:

Submission December 2020

Revised April 2020

Accepted May 2020

*Corresponding author:

E-mail:

muhanasjamil1@yahoo.co.id

\begin{abstract}
Eisenmenger Syndrome is congenital heart disease with pulmonary hypertension and shunting from right to left turning. Pulmonary vascular resistance defects cause enlargement of the pulmonary arteries, as well as enlargement of the left ventricle. Hypoxia alveoli cause reversible vasoconstriction which increases the pressure of the pulmonary wedges. Physiological effects of inhaled nitric oxide therapy result in selective pulmonary vasodilation such that the pulmonary wedge pressure can be reduced. Although it does not affect the cardiac output and systemic arterial pressure. Inhaled nitric oxide in the pulmonary vascular is selective as it is activated by hemoglobin; selective vasodilatation in the ventilated region, local hypoxia alveoli constricts the surrounding vascular tissue and redistributes better and higher intraalveolar oxygen pressure to the ventilated lungs. Inhaled nitric oxide improves this process by increasing blood flow into a well-ventilated lung; bronchodilators; pulmonary surfactant; combining high concentrations of inspired oxygen with high concentrations of inhaled nitric oxide reduces minimum surface tension.
\end{abstract}

Keywords: inhalation nitric oxides, Eisenmenger syndrome, pulmonary vascular

\section{Introduction}

Research on Nitric Oxide (NO) continues to grow since the identification of this molecule in 1987 has the same effect as the endotheliumderived relaxing factor (EDRF) [1]. Many views about the mechanism of action of NO were put forward, since the application of inhaled nitric oxide (INO) in the laboratory and patients with primary pulmonary hypertension in 1991. In children and adults who experience severe pain and hypoxemia, INO improves arterial oxygenation and decreases pulmonary arterial hypertension selectively [2]. The combination of INO with a ventilator can reduce the need for extracorporeal membrane oxygenation (ECMO) [1, 3-7].

Eisenmenger Syndrome (ES) is congenital heart disease with pulmonary hypertension and shunting turning from right to left (R-L). The prevalence is around 7\% in adulthood. And more in women than in men. His life expectancy decreased significantly, and few reached the age of 40 or 50 years. The cause of ES death is right ventricle failure and hypotension which causes cardiogenic shock [8-11].

Management of ES is with oxygens, vasodilators, anticoagulants, and phlebotomy. Furthermore, surgery if pulmonary vascular resistance is less than systemic vascular resistance. Cardiopulmonary transplants offer new hope [8-11].

In cyanotic congenital heart disease that persists into adulthood, decreased blood vessel resistance causes an increase in R-L shunting by increasing cyanosis. Decreased oxygenation causes impaired growth in the fetus. In ES with 
secondary pulmonary hypertension or in primary pulmonary hypertension, decreased peripheral resistance when associated with decreased preload induced by changes in position or bleeding during labor will cause hypotension. It causes the right ventricle, unable to maintain blood flow through pulmonary arteriolar tissue with high resistance. Circumstances that cause extensive thrombosis in small blood vessels in the pulmonary arterial system that occur in the postpartum period also cause increasingly severe pulmonary hypertension [11-14].

This Literature review is intended to provide an overview of the use of nitric oxide which has an effect on local blood vessels in the lungs in patients with congenital heart disease with defects in the heart wall both in the ventricles and atria which cause blood shunting from right to left.

\section{Inhalation Nitric Oxide}

Chemical and Biochemical Properties

Nitric oxide (NO) is colorless, odorless, and relatively soluble in water. NO in the environment comes from the combustion and lighting processes. The atmospheric NO concentration is between 10-500 parts per billion (ppb) but can exceed 1.5 parts per million (ppm) in areas with heavy traffic. The safe limit of NO is $25 \mathrm{ppm}$ and $5 \mathrm{ppm}$ for nitrogen dioxide $\left(\mathrm{NO}_{2}\right)[1,15]$.

The target molecule activates nitric oxidation. T1/2 a few seconds. The primary metabolism is $\mathrm{NO}_{3}$. $\mathrm{NO} 90 \%$ is absorbed during inhalation and expressed as $\mathrm{NO}_{3}$ in urine $70 \%$. $30 \%$ become $\mathrm{NO}_{2}$ secreted in the mouth through saliva. $\mathrm{NO}_{2}$ is partially converted to $\mathrm{N}_{2}$ in the stomach and $\mathrm{NO}_{2}$ in the small intestine and then converted to ammonia, reabsorbed and converted to urea $[1,10,16]$.

For commercial purposes, NO is made from the reaction between sulfur dioxide and nitric acid, or oxidation of ammonia with a platinum catalyst at temperatures $>500^{\circ} \mathrm{C}$. In anaerobic conditions, NO can be stored for several years [1].
Physiological Effects of INO Therapy

The physiological functions of INO therapy for the cardiorespiratory system include the following:

1. Selective pulmonary vasodilation

a. Hypoxia alveoli

Hypoxia alveoli cause reversible vasoconstriction, thereby increasing pulmonary wedge pressure. Inhaled nitric oxide lowered it. Moderate cardiac output and systematic arterial pressure are not affected $[1,2,9,10,17]$. Selective in pulmonary because it is activated by hemoglobin $[1,8,10]$.

b. Selective vasodilation in ventilated areas

Local alveolar hypoxia constricts the surrounding blood vessel tissue and redistributes blood flow to a better-ventilated lung and higher intraalveolar oxygen pressure. Inhaled nitric oxide enhances this mechanism by increasing blood flow through a wellventilated lung $[1,2,8,10,17]$.

2. Bronchodilators $[1,17]$.

3. Pulmonary surfactants

The combination of high concentrations of inspired oxygen and high concentrations of INO reduces the minimum surfactant surface tension in newborn pigs $[1,18]$.

\section{Effectiveness of INO}

There are several known constraints related to the use of INO therapy. To increase the effectiveness of INO therapy, a strategy is needed to overcome these obstacles.

1. Hyporesponsiveness to INO

The mechanisms are (a) the presence of endogenous NO, (b) the catecholamine effect on sepsis, (c) decreased pulmonary cyclic Guanine Mono Phosphate in sepsis, (d) increased vascular superoxide $\left(\mathrm{O}_{2}{ }^{*}\right)$, (e) decreased cGMP plasma, and (f) ABO (genetic) blood type, where $\mathrm{A} / \mathrm{O}$ blood group has a more significant increase in the $\mathrm{PaO}_{2} / \mathrm{FiO}_{2}$ value. The incidence rate ranges from $30-45 \%[1,19]$.

2. Strategies to increase responses to INO (1)
a. Phosphodiesterase inhibitors
b. Almitrine infusion c. Inhibition of vascular superoxide
production
d. Partial liquid ventilation 


\section{Slide Effects of INO}

Many benefits can be obtained by using INO as a therapeutic modality. Besides that, several things need to be monitored for several things related to INO therapy:

1. Be careful of left ventricular disorders, which can cause pulmonary edema $[1,4]$.

2. The sudden termination of INO causes a withdrawal $[1,4,20]$.

3. Bleeding time in ARDS (acute respiratory distress syndrome), INO decreases platelet aggregation and agglutination (in vitro). In vivo, studies were not affected $[1,4,20]$.

\section{Slide Nitric Oxide Toxicity}

Toxicity that needs attention is

$[1,4,9,10,18,21,22]$.

Methemoglobinemia:

1. $\mathrm{NO}_{2}$ formation.

2. Cellular toxicity

For that, we need an INO security monitor with $[1,22]$ :

1. Levels of $\mathrm{NO}$ and $\mathrm{NO}_{2}$.

2. Monitor device calibration.

3. Methemoglobin levels.

4. Use of certified tanks.

5. Use of low concentrations

\section{Eisenmenger Syndrome}

Definition and Prevalence

Eisenmenger Syndrome (ES) is congenital heart disease with pulmonary hypertension and shunting turning from right to left (R-L). It is around 7\% in adulthood and more in women $[9,11,23,24]$.

\section{Cardinal Signs}

Pulmonary artery pressure is almost the same as systematic pressure. Bidirectional shunting or R-L. Pulmonary vascular resistance to more than $7.5 \mathrm{mmHg} / \mathrm{L} / \mathrm{min}$. The right ventricle and pulmonary artery always enlarge $[8,11]$.

\section{Cardinal Signs}

1. Symptoms and Signs

Symptoms that appear are tight and blue since the baby. Complaints of tightness vary with the development of age, hemoptysis, chest pain palpitations, and fainting attacks since adolescents and young adults. History of pneumonia, heart failure, eating disorders, susceptible to frequent infections in L-R but not in R-L $[8,11,24]$

While the signs are cyanosis, sugar cane fingers, a wave that is prominent in jugular venous pulsation, the heart is not too enlarged and calm, the right ventricle lifts. The closure of the pulmonary valve is palpable. There is a systolic ejection click followed by a short systolic ejection murmur. A loud second heart sounded. Also, early diastolic murmurs. Signs of heart failure are rare, but cyanosis and polycythemia are common $[8,11,23]$.

2. Diagnostic Aids

Electrocardiography shows right ventricular hypertrophy. The thorax looks like a trunk and the main branches of the enlarged pulmonary artery. Heart slightly enlarged. Hematocrit to assess the progression of the disease. Echocardiography sees the shunting site. Cardiac catheterization to establish the diagnosis and show that pulmonary artery pressure and pulmonary vascular resistance increase. Measurement of pulmonary wedge pressure is critical to determine whether the lesion can be corrected or not $[8,23,24]$.

\section{Differential Diagnosis}

It must be distinguished from pulmonary hypertension due to lesions obtained from increased left atrial pressure. Primary pulmonary hypertension and thromboembolic pulmonary hypertension must be excluded. A history of murmurs and cyanosis since children is beneficial in identifying congenital lesions. In severe pulmonary hypertension can open the foramen ovale and cause R-L shunting, causing misdiagnosis of congenital lesions. Peripheral pulmonary artery stenosis also causes physical signs of increased primary pulmonary arterial pressure [8,11,2-25].

\section{Complications}

Complications include progressive polycythemia and pulmonary thromboembolism. Pulmonary infarction and bleeding from plexiform angiomatous lesions around the pulmonary artery. With the presence of polycythemia, there is a tendency to bleeding a lot. If Hct (hematocrit) is more than $60 \%$ easy to bruise, bleeding gums, 
petechiae, and hemoptysis. Endocarditis and artemia can occur $[8,11,23,24]$

\section{Management}

\section{Medical Management}

- Supportive Therapy

Therapy for patients with Eisenmenger Syndrome previously focused solely on palliative therapy or heart-lung transplantation $[11,26]$. The long-term supply of oxygen is controversial. Nighttime oxygen delivery with a 2year follow-up period did not affect functional capacity, disease course, and patient survival $[27,28]$. Oxygen delivery needs to be considered in cases where oxygen administration causes an increase in oxygen saturation and decreased symptoms $[8,11,23$ 25,28].

Patients with Eisenmenger Syndrome with hyperviscosity associated with increased erythrocyte production can be performed phlebotomy with isovolumic fluid replacement, usually hematocrit> 65\% [26]. However, routine phlebotomy should be avoided because it causes anemia, disruption during exercise, decreased quality of life, and an increased risk of thromboembolic events $[8,11,23-25,27]$.

\section{- Medicinal Therapy}

Giving diuretics can be given to patients with Eisenmenger Syndrome with congestive symptoms, but has a risk of hyperviscosity $[11,26]$.

Anticoagulants in Eisenmenger Syndrome must be given with caution, given the risk of hemoptysis, stroke, and bleeding. Coumarinderived anticoagulants are still acceptable but limited to atrial fibrillation, intracardiac mechanical prosthesis, and advanced heart failure $[8,11,23,25,29,30,31]$.

The use of Calcium channel blockers in patients with Eisenmenger Syndrome is not recommended because it can reduce systemic arterial pressure and increase right to left shunting, which causes syncope and sudden death $[11,26]$.

Endothelin Receptor Antagonist (ERA). Endothelin-1 plays a role in the structural and functional abnormalities of pulmonary arteries. There are three types of approved ERA groups, namely bosentan, macitentan (dualERA), and ambrisentan (mono-ERA). Bosentan is a dual endothelin receptor oral antagonist preparation that functions to reduce pulmonary vascular pressure and resistance, reduce the incidence of inflammation and vascular fibrosis on long-term observation [27,20]. The BREATH-5 study (Bosentan Randomized Trial of Endothelin Antagonist Therapy-5), showed that bosentan in patients with Eisenmenger Syndrome with a functional WHO class III reduced Pulmonary Vascular Resistance (PVR) significantly and improved exercise capacity compared to placebo [26,29,30-32]. The ESC guidelines currently support giving Bosentan as the first choice for sufferers of functional class III-IV Eisenmenger syndrome [27,31]. The side effects are headache, facial flushing, and nasopharyngitis. The provision of ERA requires routine blood test monitoring because it can induce anemia and liver disorders $[11,27,28]$

Phosphodiesterase Type 5 Inhibitors. Oral PDE-5 inhibitors have several benefits, namely increasing vasodilatation of Nitric Oxide (NO) by increasing cGMP concentrations, having antiproliferative effects of vascular smooth muscle cells, and increasing contractility of right ventricular hypertrophy $[11,30]$.

SUPER-1 research (Sildenafil use in Pulmonary Arterial Hypertension) shows that Sildenafil can improve exercise capacity in pulmonary arterial hypertension. Also, it has a short-term safety and efficacy profile. Sastry et al. Prove that the administration of sildenafil for four months is comparable to that observed in the SUPER-1 study $[11,30]$.

Zhang et al. study of 168 patients with Eisenmenger Syndrome who were treated with sildenafil for one year showed improvement in pulmonary hemodynamics. Mukhopadhyay et al. research showed 16 Eisenmenger sufferers treated with tadalafil experienced a decrease in PVR, mean PAP, and increased oxygen saturation for 12 weeks $[11,31,33]$.

The risk of liver damage is not found in patients with Eisenmenger Syndrome who are treated with PDE- 5 oral inhibitors and thus do not require routine blood tests $[11,27]$. Prosta- 
cyclin Analog. Preparations in the analog prostacyclin group, among others epoprostenol, have the most potent effect and can only be given intravenously continuously because of the short half-life of only a few minutes, but can be at risk of long-term paradox embolism and sepsis [24,27]. The administration of intravenous epoprostenol increased functional capacity, oxygen saturation and exercise capacity significantly in 8 sufferers of ES after three months of therapy $[11,26]$.

Treprostinil is also a prostacyclin analog with a half-life of 3 hours, can be used subcutaneously and intravenously. Long-term use of treprostinil provides the same survival benefits as intravenous epoprostenol [11, 24,28].

Beraprost is an oral prostacyclin analog. In randomized controlled trials, it was found not to show a significant effect. During the initial phase of treatment, the administration of beraprost shows little progression lasting up to 6 months. Nevertheless, after one year, there is no longer a difference between the beraprost and the placebo group. Beraprost does not play an essential role in the treatment of PAHs associated with congenital heart disease and Eisenmenger Syndrome, so it is no longer used in $\mathrm{Eu}$ rope (28); (30). Prostacyclin analogs are included in the second or third line in the treatment algorithm for pulmonary hypertension $[11,24,27]$.

\section{- Combination Therapy}

The use of combination therapy can be considered in patients with symptomatic ES who do not improve on first-line drug therapy but need to be vigilant because of unknown interactions that cause toxicity. Giving sildenafil and bosentan combination therapy in 21 patients with ES, a significant increase of $6 \mathrm{MWD}, \mathrm{PVR}$, and pulmonary blood flow compared with placebo $[11,26,34]$.

\section{- Surgical Management}

If pulmonary vascular resistance is equivalent to systematic and little or no L-R shunting, closure of intracardiac defects or extracardiac defects is contraindicated. Cardiopulmonary transplantation gives new hope $[8,11,25,35]$.

\section{- Prognosis}

Life expectancy decreased significantly, and few reached the age of 40 or 50 years. The cause of death in ES is right ventricular failure and hypotension which causes cardiogenic shock $[8,10,11,23,24,25]$.

Maternal mortality in the presence of ES reported as $30-50 \%$ and pregnancy should be avoided [36].

\section{Conclusion}

Eisenmenger Syndrome is congenital heart disease with pulmonary hypertension and shunting turning from right to left. The prevalence is $7 \%$ in adulthood. More occur in women. The life expectancy of people with ES has decreased significantly, and few reach the age of 40 or 50 years. The cause of death is a ventricular failure due to hypotension, which causes cardiogenic shock.

Management of patients with ES is oxygenation, anticoagulants, vasodilators, and phlebotomy. Surgery is only performed if pulmonary vascular resistance is less than systemic vascular resistance. Cardiopulmonary transplantation provides new hope for sufferers.

In cyanotic congenital heart disease that persists into adulthood, decreased blood vessel resistance causes an increase in R-L shunting by increasing cyanosis. Decreased oxygenation causes impaired fetal growth. Eisenmenger Syndrome with secondary pulmonary hypertension or primary pulmonary hypertension, decreased peripheral resistance when associated with decreased preload induced by changes in position or bleeding during labor will cause hypotension. This condition causes the right ventricle not to be able to maintain blood flow through pulmonary arteriolar tissue with high resistance. Also, the conditions that cause extensive thrombosis in the pulmonary artery's small vessel system postpartum cause severe pulmonary hypertension.

Inhalation nitric oxide is a potent and selective pulmonary vasodilator. In ES, relaxation of the endothelium-dependent pulmonary blood vessels is disturbed. Patients with ES who inhale NO can directly reduce pulmonary hypertension and increase oxygenation due to the optimization of the ventilation-perfusion rela- 
tionship. Inhalation nitric oxide also has an antithrombotic effect and is also used in preparation for a pulmonary heart transplant.

\section{References}

1. Steudel W, Hurford E. WE, Zapol WM (1999) Inhaled nitric oxide: Basic biology and clinical applications. Anesthesiology 91(4):1090-121.

2. Anas M, Triastuti N, Airlangga MP (2020) Role of Inhaled Nitric Oxides In Pregnancy With Eisenmenger Syndrome. Qanun Med J Fac Med Muhammadiyah Surabaya 4(1):11-26.

3. Anggard E (1994) Nitric Oxide: mediator, murderer, and medicine. Lancet 343:1199-206.

4. Atz AM, Wessel DL (1997) Inhaled nitric oxide in the neonate with cardiac disease. Semin Perinatol 21(5):441-55.

5. Chen C (1997) Nitric Oxide For Newborns Nitric Oxide Proves Effective In Treating Newborns With LifeThreatening Lung Disorder [Internet]. Available from: cwchen@ITSA.UCSF.EDU

6. Finer NN, Barrington KJ (1997) Nitric oxide in respiratory failure in the newborn infant. In: Seminars in Perinatology. Elsevier, p. 426-40.

7. Barrington KJ, Finer N, Pennaforte T, Altit G (2017) Nitric oxide for respiratory failure in infants born at or near term. Cochrane Database Syst Rev. 2017(1): 1-9.

8. Smith C (1984) Congenital heart disease, with special reference to the indications and. In: Hahnemann monthly. 6th Editon. Appleton \& Lange, p. 208-14.

9. Vaishnava H (1957) Heart diseases in pregnancy. In Journal of the Indian Medical Association, 6th Editon. Appleton \& Lange, p. 228-33.

10. Barry AP, Meagher D, O'dwyer E (1956) Heart disease in pregnancy. In: Journal of the Irish Medical Association. 8th Editio. McGraw-Hill, Inc., p. 82-3.

11. Brennan K, Hatch DM (2018) Eisenmenger's Syndrome. In: Consults in Obstetric Anesthesiology. Switzerland: Springer Nature, p. 185-7.

12. Gibbs CP (1988) Anesthetic Management of High-Risk Mother. In: Sciarra Gynecology and Obstetrics. J. B. Lippincott Company, p. 1-11.

13. Mahomed K (1997) Heart Disease in Pregnancy. In: BMJ. J.B. Lippincott Company, p. 67.

14. Lust KM, Boots RJ, Dooris M, Wilson J (1999) Management of labor in Eisenmenger syndrome with inhaled nitric oxide. Am J Obstet Gynecol. 181(2):419-23.

15. Korde Choudhari S, Chaudhary M, Bagde S, Gadbail AR, Joshi V (2013) Nitric oxide and cancer: A review. World J Surg Oncol. 11(1):118.
16. Cheung PY, Salas E, Schulz R, Radomski MW (1997) Nitric oxide and platelet function: Implications for neonatology. Semin Perinatol 21(5):409-17.

17. Omer N, Rohilla A, Rohilla S, Kushnoor A (2012) Review article nitric oxide : role in human biology. Int J Pharma Sci Drug Res. 4(2):105-9.

18. Kinsella JP, Abman SH (1997) Inhaled nitric oxide in the premature infant: Animal models and clinical experience. In: Seminars in Perinatology. Elsevier, p. 418-25.

19. Anas M, Marlina U (2018) Penggunaan Nitrovasodilator Sebagai Donor Oksida Nitrik Pada Preeklamsia. In: Proceeding Annual Meeting APKKM Ke 6 Surabaya [Internet], p. 1-27. Available from: http://journal.umsurabaya.ac.id/index.php/Pro/search/search?simpleQuery =anas\&searchField=query

20. Kim S, Hyun J, Kim H, Kim Y, Kim E, Jang J, et al. (2011) Effects of Lead exposure on nitric oxide-associated gene expression in the olfactory bulb of mice. Biol Trace Elem Res. 142(3):683-92.

21. Gillis HC, Gupta S, Skoglund A, Ritter S (2018) Changing Ordering Practice for Inhaled Pulmonary Hypertension Treatment in the Icu. Am Acad Pediatrics.

22. Satoh T, Xu Q, Wang L, Gladwin MT (2018) Hemolysismediated toxicity during cardiopulmonary bypass ameliorated by inhaled nitric oxide gas. American Journal of Respiratory and Critical Care Medicine. American Thoracic Society 198, 1244-6.

23. Weale J, Kelleher AA (2018) Adult congenital heart disease. In: Anaesthesia and Intensive Care Medicine. McGraw-Hill, Inc., 285-91.

24. Scholz TD, Reinking BE (2012) Congenital Heart Disease. In: Avery's Diseases of the Newborn (Ninth Edition). 24th editions. USA: Mc Graw Hill, 762-88.

25. Gaine S (2000) Pulmonary hypertension. In: Journal of the American Medical Association. McGraw-Hill, Inc., 3160-8.

26. Beghetti M, Galiè N (2009) Eisenmenger Syndrome. A Clinical Perspective in a New Therapeutic Era of Pulmonary Arterial Hypertension. J Am Coll Cardiol. 53(9):733-40.

27. Vongpatanasin W, Brickner ME, Hillis LD, Lange RA (1998) The Eisenmenger syndrome in adults. Ann Intern Med. 128(9):745-55.

28. Dimopoulos K, Wort SJ, Gatzoulis MA (2014) Pulmonary hypertension related to congenital heart disease: A call for action. Eur Heart J. 35(11):42.

29. Trojnarska O, Plaskota K (2009) Therapeutic methods used in patients with Eisenmenger syndrome. Cardiol J. 16(6):500-6.

30. D’Alto M, Diller GP (2014) Pulmonary hypertension in adults with congenital heart disease and Eisenmenger syndrome: 
Current advanced management strategies. Heart 100(17):1322-8.

31. Hjortshøj CS, Jensen AS, Søndergaard L (2017) Advanced Therapy in Eisenmenger Syndrome. Cardiol Rev. 25(3):12632.

32. Huang J Bin, Liang J, Zhou LY (2012) Eisenmenger syndrome: Not always inoperable. Respir Care 57(9):1488-95.

33. Fukushima H (2015) Update on medical treatment of patients with Eisenmenger syndrome. Int Heart J. 56(Supplement): S4-7.

34. Zhang ZN, Jiang $X$, Zhang $\mathrm{R}$, Li $\mathrm{XL}, \mathrm{Wu} B X$, Zhao $\mathrm{QH}$, et al. (2011) Oral sildenafil treatment for Eisenmenger syndrome:
A prospective, open-label, multicentre study. Heart 97(22):1876-81.

35. McCarthy PM, Rosenkranz ER, White RD, Rice TW, Sterba R, Vargo R, et al. (1991) Single-Lung transplantation with atrial septal defect repair for Eisenmenger's syndrome. Ann Thorac Surg. 52(2):300-3.

36. Karelkina E, Irtyuga O, Kokonina Y, Yakubov A, Li O, Mazurok $\mathrm{V}$, et al. (2018) P3465The pregnancy outcomes and delivery in women with Eisenmenger's syndrome. European Heart Journal 39: 3466. 